\author{
Armin Bećirević, Damir Kolić, Tin Matulja \\ E-mail: abecir@live.com \\ Tehnički fakultet, Sveučilišta u Rijeci, Vukovarska 58, Rijeka
}

\title{
Izrada gantograma dokovanja na plutajućem doku
}

\begin{abstract}
Sažetak
Brodovi i razni drugi pomorski objekti nakon određenog vremena provedenog u ekspoataciji, ili zbog nekih izvanrednih okolnosti kao što su havarije, moraju obaviti remont u nekom od remontnih brodogradilišta. Objekti se najčešće dokuju zbog izvođenja raličitih radova vezanih uz podvodni dio trupa ili zbog periodičnih pregleda vještaka Registra i sl. Primjeri takvih radova su sanacije oštećenja trupa, radovi na propeleru, listu kormila, AKZ tretman podvodnog dijela trupa. Remont se najčešće odvija na plutajućim dokovima na kojima se brod ili neki pomorski objekt relativno jednostavno digne iz vode. Uz pomoć plutajućih dokova remont se može izvršiti jednostavno i brzo. Ovaj rad pokazuje detaljan prikaz procesa te akcije potrebne za izvršavanje nekog od istih te njihova moguća poboljšanja.
\end{abstract}

Ključne riječi: gantogram, dokovanje, plutajući dok, procesi, remontno brodogradilište

\section{Uvod}

Od samih početaka brodogadnje uvijek je bilo potrebe za popravcima ili modifikacijama brodova, te tako i danas ali uz upotrebu razvijenijih tehnologija. Danas se remont ili kontrole izvode u suhim dokovima koji mogu, najčešće, biti „floating” ili „basin dry docks”. Zbog sve veće potrebom za remontom, kroz povijest, razvila su se remontna brodogradilišta kojima je cilj isključivo izvoditi preinake i/ili remont brodova te nekih drugih plovnih objekata. Prilikom dokovanja brod brodovlasniku ,gubi“ novac, jer vrijeme provedeno u remontu je vrijeme u kojem brod ne donosi nikakvu zaradu. Zbog toga se javlja potreba za što bržim i kvalitetnijim izvođenjem radova. A to je dovelo do rasčlanjivanja aktivnosti s ciljem boljeg razumjevanja procesa, da bi se moglo analizirati i uviditi moguća poboljšanja samih procesa tokom remonta. Jedan od važnijih procesa tokom remonta broda je dokovanje broda koje može oduzeti velik dio vremena (cijeli dan ili više) ovisno o uvjetima. Da bi smo oprimizirali tako jedan proces bilo je potrebno rasčlaniti u manje segmente u kojima je moguće uvijdeti moguća poboljšanja. $\mathrm{U}$ to svrstavamo vrijeme trajanja dokovanja, potrebene radnike, opremu i alate, itd. $\mathrm{U}$ koncu time bi se mogao smanjiti rizik u oštećenju broda te efikasnije iskoristiti dok, smanjenje ukupnih troškova brodogradilišta, odnosno povećanjem zarade. 


\section{Opis pripreme dokovanja}

Pripremni postupak, kao i samo dokovanje ovise o karakteristikama dokovanog objekta, a na realizaciji angažirano je više djelatnika raznih zanimanja. Rad organizira i odgovorna osoba je upravitelj doka. Pripremni postupak sastoji se od više faza. Upravitelj doka sa zapovjednikom objekta, a po potrebi i sa voditeljem objekta utvrđuje uvjete (eng. docking condition), koje objekat treba zadovoljiti za ulazak u dok, prema tehničkim uputima za eksploataciju doka. Zapovjednik je dužan ispuniti tzv. Upitnik (vidite sliku 1.) koji sadrži osnovne tehničke podatke o objektu, stanje težina (prazan brod, balast, gorivo, voda, ostale težine, ukupna težina), gaz na pramcu i krmi, stanje objekta u pogledu stabiliteta (MG), zahtjevi u odnosu na opskrbu el. energijom, vodom i drugo.

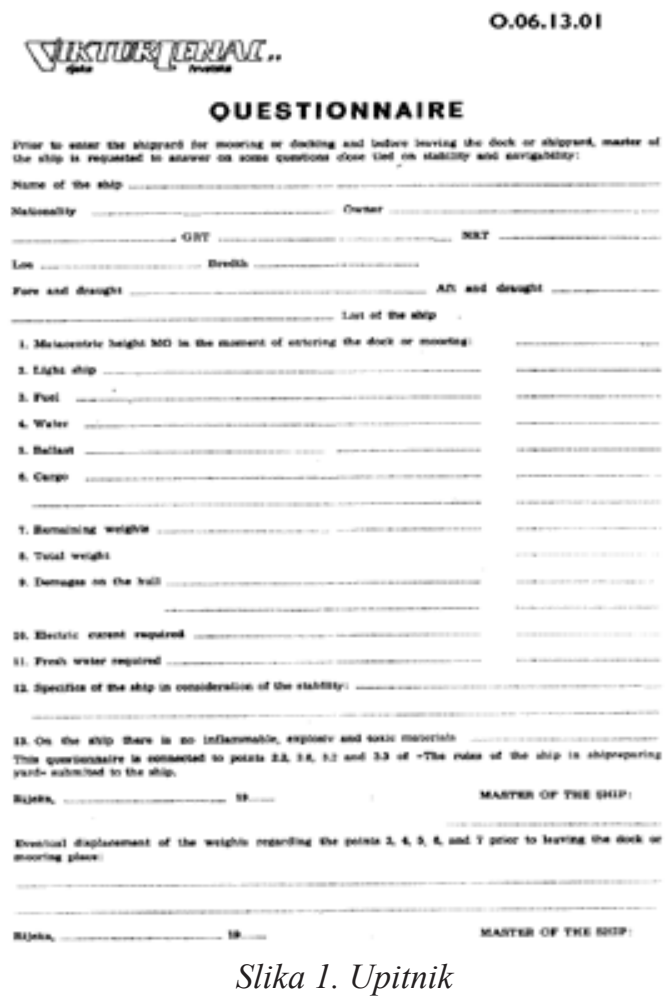

Zapovjednik treba upravitelju doka dati na uvid i potrebne nacrte. Osnovni nacrt je Plan dokovanja. Na njemu se vidi forma trupa objekta, smještaj armature na trupu (usisne košare, dubinomjer, brzinomjer, čepovi tankova, ljuljne kobilice, stabilizatori), te se na osnovu toga odredi položaj objekta u doku i vrši razmještaj centralnih i bočnih podklada. Iz Plana dokovanja određuje se i položaj Plimsol oznake, koja se koristi za 
pozicioniranje objekta u doku. Kod određivanja položaja objekta u doku u uzdužnom smislu, osnovni zahtjev odnosi se na položaj težišta objekta u odnosu na težište doka. U idealnom slučaju trebali bi se poklapati. Teži se da razlika bude što manja, osobito kad je deplasman objekta blizu maksimalnoj nosivosti doka. U slučaju dokovanja objekata nespecifičnih veličina u pogledu dužine, širine, deplasmana, trima, raspored težina, konzultira se Konstrukcioni ured brodogradilišta. U poprečnom smislu simetrale doka i objekta moraju se poklapati. Svi parametri koji određuju položaj objekta u doku, kao i sve radnje izvršene na pripremi dokovanja upisuju se u Karton, slika 2., koji se koristi prilikom slijedećeg dokovanja istog objekta ili za slične slučajeve.

Pripremne radnje za ulazak broda u dok uključuju: potapanje doka na određeni gaz, ovisno o gazu broda, pripremu priteznih vitala, konopa za tegalj, čelik-čela (čeličnih užadi) za pozicioniranje broda u doku. Dok se potapa naplavljivanjem balastnih tankova sa centralnog upravljačkog mjesta. Operater je dežurni strojar pod nadzorom upravitelja doka. Prilikom potapanja prate se instrumenti koji pokazuju pramčani i krmeni gaz, uzdužni i poprečni nagib, izvijanje i savijanje doka. Sve veličine moraju biti u skladu sa tehničkim uputstvima i vrši se stalna korekcija. Za ulazak objekta u dok koriste se pritezna vitla na pramcu doka i konopi za tegalj. Po ulasku, objekt se pozicionira u uzdužnom i poprečnom smislu na poziciju definiranu u pripremnom postupku. Pozicioniranje se vrši pomoću čelik-čela i priteznih vitla na pramcu i krmi doka.

0.06 .13 .02

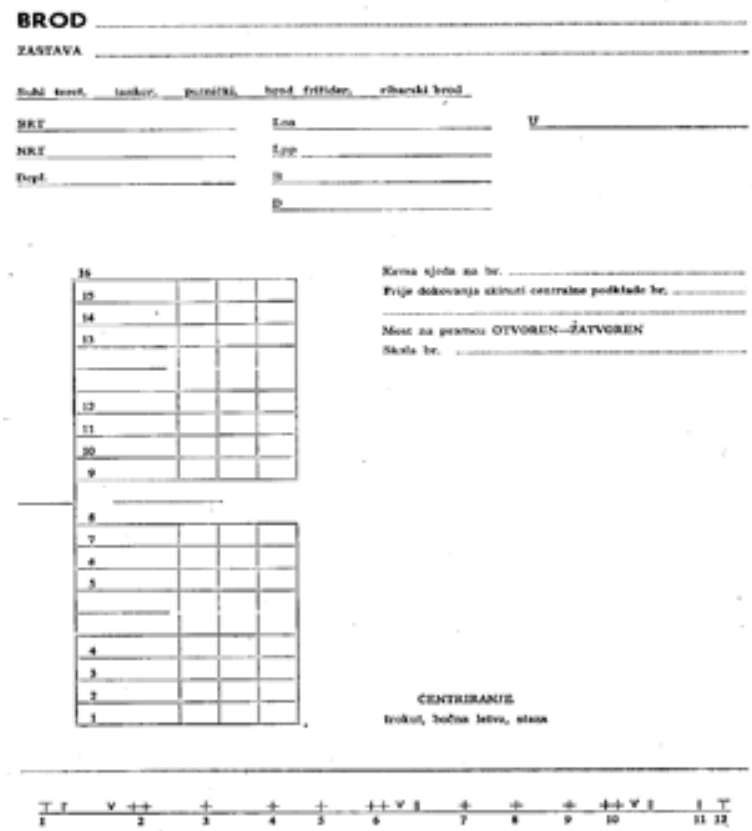

Slika 2. Karton 
Uzdužno pozicioniranje određeno je položajem Plimsol oznake u odnosu na oznaku glavnog rebra doka, a poprečno, prema oznakama na centralnim podkladama ili mjerenjem udaljenosti paralelnog srednjaka na pramčanom i krmenom dijelu od tornja doka. Po završetku pozicioniranja diže se dok otvaranjem izlaznih ventila balasta i ventila balastnih tankova te uključivanjem balastnih sisaljki. Do momenta dodira kobilice objekta i centralnih podklada doka vrši se korekcija pozicioniranja. Radom balastnih sisaljki i ventila balasta upravlja dežurni strojar (ili električar doka) prema uputama upravitelja doka. Tijekom dizanja doka stalno se prati stanje sistema objekatdok i vrši korekcija uzdužnog i poprečnog nagiba i savijanja. Ovisno o formi podvodnog dijela objekta podižu se bočne podklade koje ga osiguravaju od naginjanja budući da izranjanjem postepeno gubi vlastiti stabilitet. Broj upotrebljenih bočnih podklada kao i veličine sila kojima su opterećene bilježe se u poseban formular slika 3.

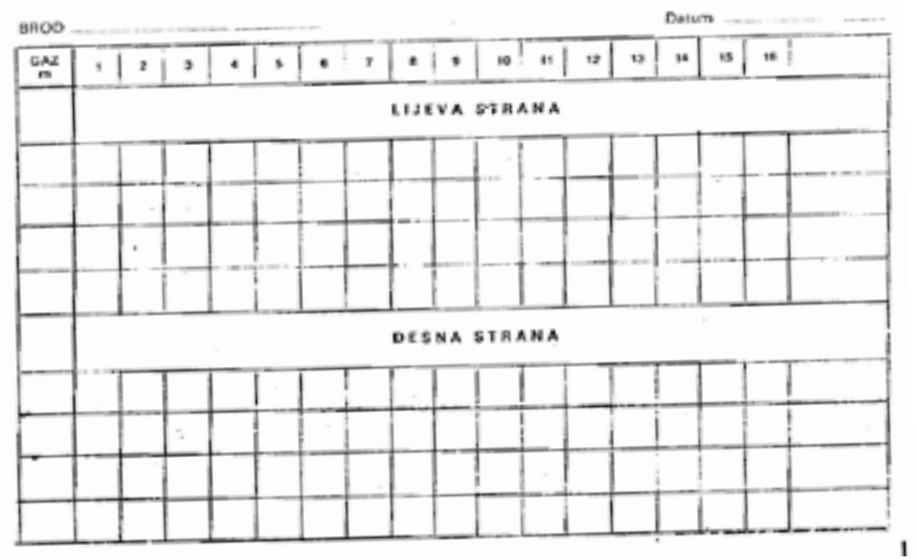

Slika 3. Formular za potklade

Točno vrijeme svake faze u procesu dokovanja od ulaska objekta u dok do završetka dokovanja upisuje se u Protokol dokovanja slika 4., koji se pohranjuje u Karton dotičnog objekta. Neposredno nakon dokovanja pregledava se stanje objekta na doku. Po potrebi izvrši se dodatno podklađivanje.

Objekat se upisuje u Knjigu dokovanih brodova, koja sadrži osnovne karakteristike objekta, vrijeme dokovanja i izdokovanja. 


\section{Brodogradiliste \\ "VIKTOR LENAC"}

Broj doka

\begin{tabular}{|c|c|c|c|}
\hline $\begin{array}{l}\text { IME BRODA } \\
\text { LUKA PRIPADNOSTL } \\
\text { BRT } \\
\text { DURNA } \\
\text { GAZ pramac: }\end{array}$ & $\begin{array}{l}\text { NRT } \\
\text { SLRINA } \\
\text { kima: }\end{array}$ & \multicolumn{2}{|c|}{$\begin{array}{l}\text { Radni nalog: } \\
\text { Nalog za dobovanje: }\end{array}$} \\
\hline Dokovanje & Vrijeme & Izdokovanje & Vrijeme \\
\hline Doxum: & & Datum: & \\
\hline Vodostaj: & & Voobotaj: & \\
\hline \multirow{2}{*}{$\begin{array}{c}\text { Gar doka prana: } \\
\text { Krma: }\end{array}$} & & Sts so broda: & \\
\hline & & Potetak plavdjenja doka: & \\
\hline \begin{tabular}{|l} 
Nogib doka: \\
\end{tabular} & & Voda do vita potdiada: & \\
\hline \multicolumn{2}{|l|}{ Trim doks: } & Prestanak plavijenja rad & \\
\hline \multicolumn{2}{|l|}{ Brod u doku: } & 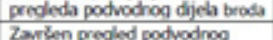 & \\
\hline $\begin{array}{l}\text { Plot s broda: } \\
\text { Brod centriza: }\end{array}$ & & 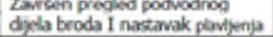 & \\
\hline \multicolumn{2}{|l|}{ Poxetak pumaanix } & Brod plivax & \\
\hline \multicolumn{2}{|l|}{ Brod sjed na potedadamds } & Istapolana struja: & \\
\hline \multicolumn{2}{|l|}{ Portiadiene boxne pothlinde: } & Raspopinn vatroparswi vod: & \\
\hline \multicolumn{2}{|l|}{ Dok na shom: } & Rirspoiena slatka vodr: & \\
\hline \multicolumn{2}{|l|}{ Zavistak pumpangax } & $\begin{array}{l}\text { Pogalen agreoat za davarije } \\
\text { struje brodu: }\end{array}$ & \\
\hline \multicolumn{2}{|l|}{$\begin{array}{c}\text { Gaz doba pramac: } \\
\text { Kma: }\end{array}$} & $\begin{array}{c}\text { Goz doka pramsc } \\
\text { Krma: }\end{array}$ & \\
\hline \multirow{3}{*}{$\begin{array}{l}\text { Defeksija opoiko-hidraulicka } \\
\text { Konkarno: } \quad \mathrm{cm} \\
\text { Konveksino: } \quad \mathrm{cm}\end{array}$} & & Nogib doka: & \\
\hline & & Trim doke & \\
\hline & & 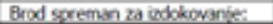 & \\
\hline \multicolumn{2}{|l|}{ Postadjen siz: } & Pillo na brod: & \\
\hline \multicolumn{2}{|l|}{ Ukoplana struja:_ V V } & Defleksija ogticklko-hidraulika & \\
\hline \multicolumn{2}{|l|}{ Spojen yatrogascri ud: } & Kankawno cc cm & \\
\hline \multicolumn{2}{|l|}{ Spojena datka vodx } & Kanwedsnoc: & \\
\hline \multirow{2}{*}{\multicolumn{2}{|c|}{$\begin{array}{l}\text { Upuken agregst za davanje } \\
\text { struje: }\end{array}$}} & Prod iz doks: & \\
\hline & & \multirow{2}{*}{\multicolumn{2}{|c|}{ 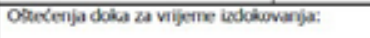 }} \\
\hline \multicolumn{2}{|c|}{ Ostétenja doka za vijerme dokrovanja: } & & \\
\hline \multicolumn{2}{|c|}{ Oparka razlog bekariga dobovanja I drugo: } & \multicolumn{2}{|c|}{ Opuska rasog ketanja irdokovarina i drugoc } \\
\hline Dok najstar: & & Dok majjsto & \\
\hline
\end{tabular}

Slika 4. Protokol dokovanja

\section{Promatrani slučaj}

Cilj promatranja dokovanja je bio analiziranje procesa dokovanja tradicinalnog remontnog brodogradilišta te $\mathrm{s}$ tim informacijama izraditi gantogram dokovanja da bi se iz njega mogla uvidjeti moguća poboljšanja u samom dokovanju.

- Dokovanje se vrši na doku broj 5 s dimenzijama:

- Duljina preko svega 201,5 m (brod max. 220 m)

- Duljina preko potklada 183,2 m

- Šrina svijetlog otvora: 33,8 m (brod max. 32,2 m)

- Visina potklada: 1,25 m (gaz broda max. 7,7m) 
Procesi su prikazani kroz akcije zabilježenje u nizu točaka bitnih za izvođenje određenog procesa. Svi procesi koji se izvode su zabilježeni u gantogramu kao dio cjeline. Gantogram je podijeljen u 18 bitnih procesa, i njime su opisani svi radovi koji se vrše na doku ili su usko vezani za radove na doku, u obzir se nije uzelo potrebno vrijeme za izvršavanje administrativnih radova koji su opisani u 3. cjelini.

U gantogramu se dodavanje novih vrijednosti označilo zelenom bojom, dok su procesi koji ne ostvaruju nikakve dodane vrijednosti ostali u crnom, odnosno plavom. Različito su označeni jer se pokušava smanjiti količina nedodanih vrijednosti kroz optimiziranje cjelokupnog procesa.

Vidi gantogram, Prilog

Nakon što su se izvršile sve potrebne pripreme započinje se s radovima na brodu. Prvo se skidaju obraštanja i čiste se svi otvori na trupu broda. Nakon toga se prelazi na AKZ zaštitu broda, zaštite se cink protektori i započinje se s temeljnim farbanjem svih oštećenja oplate, nakon svih potrebnih korekcija. Uz AKZ zaštitu važno je napomenuti i pregled kormila, zračnost lista kormila i pad propelerne osovine. Te se obavljaju i ostali potrebni radovi na brodu, remont, preinake, itd. 


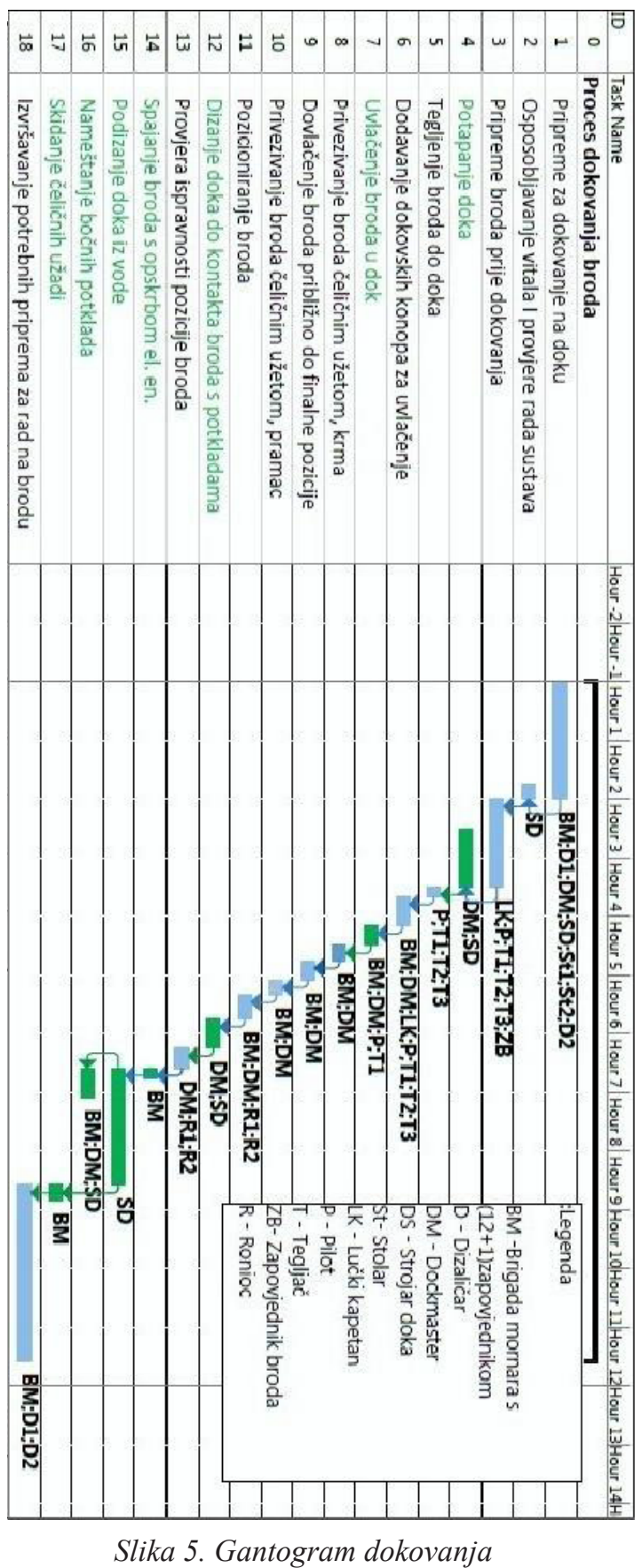




\section{Zaključci}

Korištenjem gantorama jasno se vide svi procesi tokom dokovanja broda, te na temelju toga se može doći do novih saznanja kako unaprijediti, ubrzati ili na neki drugi način optimizirati cijeli proces.

Uz gantogram su bitni i pripremni radovi jer definiraju kad će se i kako neki brod dokovati. Uređivanjem pripreme i samog dokovanja, možemo postići da dok bude neprekidno u uporabi svih 365 dana. Prilikom izdokovanja broda sve pripremne radnje za dokovanje idućeg broda se mogu prijevremeno obaviti, te odmah započeti, s većim brojem tesara i/ili mornara, s pripremom doka za novo dokovanje. S takvim načinom rada na dok bi se mogao postaviti idući brod u roko par sati, i u potpunosti bi se mogli iskoristiti svi svi potrebni kadrovi bez praznog hoda.

\section{Prilozi}

Gantogram dokovanja

\section{Zahvale}

Veliku zahvalu dugujem svom mentoru dr. sc. Damiru Koliću na pruženoj pomoći pri izradi rada, te svim informacijama i vremenu koje mi je pružio.

Također se zahvaljujem svojoj voditeljici stručne prakse dipl. ing. Sanji Jurčić na svoj pomoći tokom mog boravka u brodogradilištu „Viktor Lenac“

\section{Literatura}

1. „DOCKMASTER TRAINING MANUAL“, by HEGER DRY DOCK, INC. June, 2005 


\title{
Gant Chart of Vessel Docking onto a Floating Dry Dock
}

\begin{abstract}
Vessels and other types of maritime objects after spending a specific amount of time in exploitation, or due to some special circumstances such as accidents, must undergo repair in a repair yard. Vessels are usually docked due to the execution of different types of work related to the underwater part of the hull or due to periodical inspections by classification society experts. Examples of those works include repairs of damaged hull, propeller work, rudder work, anti-corrosive treatment of the underwater hull part. Repair is usually performed on the floating docks upon which the vessel or some other maritime object is relatively easily raised from the sea. With the help of floating dry-docks, repair work can be performed relatively easily and efficiently. This paper explains the detailed process and activities needed for succesful execution and suggests realistic improvements to improve the efficiency of the entire dry-docking process.
\end{abstract}

Keywords: Gantt chart, dry-docking, floating dry-dock, processes, repair shipyard 
